\title{
Association of the transforming growth factor $B 1$ promoter polymorphism, C-509T, with smoking status and survival in advanced non-small cell lung cancer
}

\author{
YOSUKE TOGASHI $^{1}$, KATSUHIRO MASAGO ${ }^{1}$, SHIRO FUJTA $^{2}$, YOUNG HAK KIM ${ }^{1}$, YUICHI SAKAMORI ${ }^{1}$, \\ YUKIMASA HATACHI ${ }^{1}$, AKIKO FUKUHARA ${ }^{1}$, HIROKI NAGAI ${ }^{1}$, TADASHI MIO ${ }^{1}$ and MICHIAKI MISHIMA ${ }^{1}$ \\ ${ }^{1}$ Department of Respiratory Medicine, Graduate School of Medicine, Kyoto University, Kyoto; \\ ${ }^{2}$ Division of Integrated Oncology, Institute of Biomedical Research and Innovation, Kobe, Japan
}

Received July 9, 2010; Accepted October 6, 2010

DOI: $10.3892 /$ or.2010.1098

\begin{abstract}
Transforming growth factor $\beta$ (TGF- $\beta$ ) signaling can inhibit tumor growth in developing tumors. However, it promotes tumor invasiveness and metastasis in late-stage tumors. A number of TGF- $\beta$ gene polymorphisms have been identified that can affect the survival of patients with advanced non-small cell lung cancer (NSCLC). In this study, we investigated the association of the TGF- $\beta 1$ polymorphism, C-509T, with survival in patients with advanced NSCLC. Japanese patients who were treated for unresectable advanced NSCLC between April 2003 and March 2008 at Kyoto University Hospital, were enrolled in this study. Analyses of genotype associations with survival outcomes were performed using statistical tests. The median survival of patients with the TT genotype was shorter, although not significantly, than that of patients with either the CT or CC genotype. Based on both univariable and multivariable analyses, the TGF- 31 polymorphism, C-509T, was not associated with prognosis. In patients with a smoking status of $<40$ pack-years, the median survival was significantly shorter with the TT genotype than with the CT or CC genotype. Based on univariable analysis, stage IV cancer and the TT genotype had a significant prognostic effect on survival. Based on multivariable analysis, the TT genotype was a significantly independent prognostic factor for survival. There was no association between the TGF- $B 1$ polymorphism, C-509T, and survival in patients with advanced NSCLC. In patients with a smoking status of $<40$ pack-years, however, the TGF- $\$ 1$ polymorphism, C-509T, was significantly associated with the prognosis of
\end{abstract}

Correspondence to: Dr Katsuhiro Masago, Department of Respiratory Medicine, Graduate School of Medicine, Kyoto University, 54 Shogoin-Kawaracho, Sakyo-ku, Kyoto 606-8507, Japan

E-mail: masago@kuhp.kyoto-u.ac.jp

Key words: non-small cell lung cancer, transforming growth factor $ß 1$, single nucleotide polymorphism, survival, cigarette smoking advanced NSCLC, and the TT genotype was an independent prognostic factor for poor survival.

\section{Introduction}

The transforming growth factor $\beta 1$ (TGF- $\beta 1$ ) belongs to a superfamily of structurally related polypeptides that also includes TGF- $\beta 2$ and - $\beta 3$, activins, nodals and bone morphogenetic proteins $(1,2)$. Alterations in TGF- $\beta$ signaling have been linked to a variety of human diseases, including cancer and inflammation. TGF- $\beta$ signaling plays a biphasic role in carcinogenesis. During the early phase of cancer development, TGF- $\beta$ acts as a tumor suppressor by inhibiting cellular proliferation and thus promoting cellular differentiation or apoptosis (3-5). However, TGF- $\beta$ functions as a tumor promoter in the later stages of carcinogenesis. In cancer cells in which the suppressive functions of TGF- $\beta$ signaling have been overridden, TGF- $\beta$ induces cellular changes which are associated at least in part, with invasion and metastasis as a result of the stimulation of angiogenesis, suppression of the immune system and increased interaction of cancer cells with the extracellular matrix (3-5).

Many polymorphisms have been identified in the TGF- 31 gene (6-8), and some of these variants have been associated with variations in TGF- $\beta 1$ levels. Some studies have reported on the association between lung cancer and TGF- 31 polymorphisms $(9,10)$, but none have reported on the association between these polymorphisms and lung cancer survival. A C to $\mathrm{T}$ base exchange located $509 \mathrm{bp}$ from the first major transcription initiation site, has been linked to promoter activity enhancement. The $\mathrm{T}$ allele of the TGF- $\beta 1$ promoter polymorphism, C-509T, has been associated with increased serum levels of TGF- $\$ 1$ (11). We therefore investigated the association of the TGF- $\beta 1$ polymorphism, C-509T, with survival in patients with advanced non-small cell lung cancer (NSCLC).

\section{Materials and methods}

Patients. One hundred and thirty-two Japanese patients who were treated for unresectable advanced NSCLC between April 2003 and March 2008 at Kyoto University Hospital, were 
Table I. Patient clinical characteristics $(n=132)$.

\begin{tabular}{|c|c|c|}
\hline Clinical characteristics & Patients (n) & $\%$ \\
\hline \multicolumn{3}{|l|}{ Age } \\
\hline$<70$ years & 75 & 57 \\
\hline$\geq 70$ years & 57 & 43 \\
\hline \multicolumn{3}{|l|}{ Gender } \\
\hline Male & 89 & 67 \\
\hline Female & 43 & 33 \\
\hline \multicolumn{3}{|l|}{ Smoking status } \\
\hline$<40$ pack-years (never-smoker) & $68(32)$ & $52(24)$ \\
\hline$\geq 40$ pack-years & 64 & 48 \\
\hline \multicolumn{3}{|l|}{ Histological type } \\
\hline Adenocarcinoma & 99 & 75 \\
\hline Squamous cell carcinoma & 17 & 13 \\
\hline Large cell carcinoma & 2 & 1 \\
\hline Non-small cell carcinoma & 14 & 11 \\
\hline \multicolumn{3}{|l|}{ Performance status } \\
\hline $0-1$ & 118 & 89 \\
\hline $2-4$ & 14 & 11 \\
\hline \multicolumn{3}{|l|}{ Stage } \\
\hline IIIA or IIIB & 30 & 23 \\
\hline IV & 102 & 77 \\
\hline \multicolumn{3}{|l|}{ TGF-ß1 C-509T } \\
\hline $\mathrm{CC}$ & 32 & 24 \\
\hline CT & 62 & 47 \\
\hline TT & 38 & 29 \\
\hline
\end{tabular}

enrolled in this study. All patients provided written informed consent prior to enrollment. Tumor staging was performed using the seventh edition of the TNM Classification (12). This study was approved by the Ethics Committee of the Kyoto University Graduate School and Faculty of Medicine.

Genotyping. Blood samples were collected from all patients at the time of recruitment. DNA was extracted from blood samples using a QIAamp DNA extraction kit (Qiagen, Tokyo, Japan). The TGF-ß1 polymorphism, C-509T (rs1800469), was genotyped using the 5'-nuclease assay (TaqMan) with the ABI prism 7300 Sequence Detecting System (Applied Biosystems, Foster City, CA, USA).

Statistical analysis. The univariate relationships between each independent variable were examined using the $\chi^{2}$ test or Fisher's exact test. In order to evaluate risk factors associated with prognosis, a Cox proportional hazards regression model with a step-down procedure, was used. Proportional hazard assumptions were checked and satisfied. Only those variables with $\mathrm{P}$-values of $<0.20$ by univariable analysis were used for multivariable analysis. The associations between the TGF- $B 1$ polymorphism status and survival were estimated using the Kaplan-Meier method and were assessed using the log-rank test. All tests were two-tailed and P-values of $<0.05$ were
Table II. Association between the TGF-ß1 C-509T genotype and patient clinical characteristics.

\begin{tabular}{|c|c|c|c|}
\hline \multirow[b]{2}{*}{ Clinical characteristics } & \multicolumn{2}{|c|}{ TGF-ß1 C-509T } & \multirow[b]{2}{*}{ P-values } \\
\hline & $\mathrm{CC}$ or $\mathrm{CT}$ & TT & \\
\hline \multicolumn{4}{|l|}{ Age } \\
\hline$<70$ years & 55 & 20 & 0.537 \\
\hline$\geq 70$ years & 39 & 18 & \\
\hline \multicolumn{4}{|l|}{ Gender } \\
\hline Male & 64 & 25 & 0.799 \\
\hline Female & 30 & 13 & \\
\hline \multicolumn{4}{|l|}{ Smoking status } \\
\hline$<40$ pack-years & 49 & 19 & 0.825 \\
\hline$\geq 40$ pack-years & 45 & 19 & \\
\hline \multicolumn{4}{|l|}{ Histological type } \\
\hline Adenocarcinoma & 72 & 27 & 0.506 \\
\hline Other & 22 & 11 & \\
\hline \multicolumn{4}{|l|}{ Performance status } \\
\hline $0-1$ & 84 & 34 & 1.000 \\
\hline $2-4$ & 10 & 4 & \\
\hline \multicolumn{4}{|l|}{ Stage } \\
\hline IIIA or IIIB & 21 & 9 & 0.868 \\
\hline IV & 73 & 29 & \\
\hline \multicolumn{4}{|l|}{ Lung metastasis } \\
\hline Yes & 24 & 12 & 0.480 \\
\hline No & 70 & 26 & \\
\hline \multicolumn{4}{|l|}{ Bone metastasis } \\
\hline Yes & 20 & 13 & 0.120 \\
\hline No & 74 & 25 & \\
\hline \multicolumn{4}{|l|}{ Brain metastasis } \\
\hline Yes & 15 & 10 & 0.169 \\
\hline No & 79 & 28 & \\
\hline \multicolumn{4}{|l|}{ Liver metastasis } \\
\hline Yes & 8 & 6 & 0.219 \\
\hline No & 86 & 32 & \\
\hline \multicolumn{4}{|l|}{ Adrenal metastasis } \\
\hline Yes & 11 & 4 & 1.000 \\
\hline No & 83 & 34 & \\
\hline
\end{tabular}

considered to be statistically significant. All preceding statistical analyses were performed using JMP 8 software (SAS Institute, Cary, NC, USA).

\section{Results}

Patient clinical characteristics are summarized in Table I. This study included only a small subset of patients (132), due to the fact that patient selection was carried out according to 
Table III. Univariable analysis of survival.

\begin{tabular}{llll}
\hline Variables & HR & $95 \%$ CI & P-values \\
\hline Age $(\geq 70 /<70$ years) & 1.062 & $0.722-1.552$ & 0.757 \\
Gender (male/female) & 1.447 & $0.965-2.216$ & 0.0740 \\
Smoking status ( $\geq 40 /<40$ pack-years) & 1.436 & $0.977-2.112$ & 0.0658 \\
Histological type (other/adenocarcinoma) & 1.130 & $0.725-1.715$ & 0.560 \\
Performance status (2-4/0-1) & 2.411 & $1.234-4.322$ & $0.0119^{a}$ \\
Stage (IV/IIIA or IIIB) & 1.373 & $0.881-2.227$ & 0.166 \\
TGF-B1 C-509T (TT/CT or CC) & 1.355 & $0.890-2.021$ & 0.153 \\
\hline
\end{tabular}

aStatistically significant in Cox proportional hazard model analysis; $\mathrm{P}<0.05$.

Table IV. Multivariable analysis of survival.

\begin{tabular}{llll}
\hline Variables & HR & $95 \%$ CI & P-values \\
\hline Gender (male/female) & 1.313 & $0.828-2.110$ & 0.249 \\
Smoking status ( $\geq 40 /<40$ pack-years) & 1.250 & $0.811-1.933$ & 0.312 \\
Performance status (2-4/0-1) & 2.183 & $1.100-3.996$ & $0.00270^{\mathrm{a}}$ \\
Stage (IV/IIIA or IIIB) & 1.328 & $0.839-2.183$ & 0.232 \\
TGF-B1 C-509T (TT/CT or CC) & 1.250 & $0.814-1.882$ & 0.302 \\
\hline
\end{tabular}

aStatistically significant in Cox proportional hazard model analysis; $\mathrm{P}<0.05$.

willingness to particpate. All patients were Japanese, including 89 males $(67 \%)$ and 43 females $(33 \%)$, with a median age of 67 years (range, $35-86$ years). The number of dominant adenocarcinomas was $99(75 \%)$. Approximately half the patients $(64,48 \%)$ were heavy smokers ( $\geq 40$ pack-years). Fourteen (11\%) patients had the Eastern Cooperative Oncology Group performance status (PS) of 2-4, while all the others had a good PS. Regarding the TGF- 31 polymorphism, C-509T, 32 (24\%) patients had the CC genotype, $62(47 \%)$ had the CT genotype and $38(29 \%)$ had the TT genotype. This ratio was similar to previous reports of healthy Japanese individuals $(13,14)$. As summarized in Table II, no correlations existed between genotypes and clinical factors.

The median survival of patients with the TT genotype was shorter, although not significantly, than that of patients with either the CT or CC genotype (log-rank test, $\mathrm{P}=0.144$ ) (Fig. 1). A Cox regression analysis was performed on the 132 patients in order to determine the correlation between patient prognosis and clinical factors, including age ( $<70$ vs. $\geq 70$ years), gender (female vs. male), smoking status ( $<40$ vs. $\geq 40$ pack-years), histological type (adenocarcinoma vs. other), PS (0-1 vs. $2-4)$, stage (IIIA or IIIB vs. IV) and the TGF- 31 polymorphism, C-509T (CC or CT vs. TT), (Table III). Among these factors, a poor PS [hazard ratio (HR), 2.411; $95 \%$ confidence interval (CI), 1.234-4.322] had a significant prognostic effect on survival. Based on the multivariable analyses of gender, smoking status, PS, stage and the TGF- $\beta 1$ polymorphism, C-509T, a poor PS (HR, 2.183; 95\% CI, 1.100-3.996; $\mathrm{P}=0.00270$ ) was a significantly independent prognostic factor for survival (Table IV).

It is known that cigarette smoking has an enormous influence on TGF- $\beta$ signaling $(15,16)$. In order to prevent such an influence, we excluded heavy smokers from the analysis and focused on a smoking status of $<40$ pack-years $(n=68)$. Patient clinical characteristics are summarized in Table I. Regarding the TGF- 11 polymorphism, C-509T, 17 (25\%) patients had the CC genotype, 32 (47\%) had the CT genotype, and 19 (28\%) had the TT genotype. No correlations were observed between the genotypes and clinical factors for any patient (Table V). In contrast, the median survival of patients with the TT genotype was significantly shorter than that of patients with either the CT or CC genotype (log-rank test, $\mathrm{P}=0.0084$ ) (Fig. 2). In heavy smokers ( $\geq 40$ pack-years; $\mathrm{n}=64$ ), however, there was no significant difference in survival (log-rank test, $\mathrm{P}=0.38$ ) (Fig. 3). A Cox regression analysis was performed on the 68 patients who smoked for $<40$ years in order to determine the correlation between patient prognosis and the clinical factors mentioned above (Table VI). Among these factors, stage IV cancer (HR, 2.069; 95\% CI, 1.031-4.744; $\mathrm{P}=0.0401)$ and the TT genotype (HR, 2.127; 95\% CI, 1.172-3.727; $\mathrm{P}=0.0141$ ) had significant prognostic effects on survival. Based on the multivariable analyses of histological type, stage and the TGF- $\beta 1$ polymorphism, C-509T, the TT genotype (HR, 2.201; 95\% CI, 


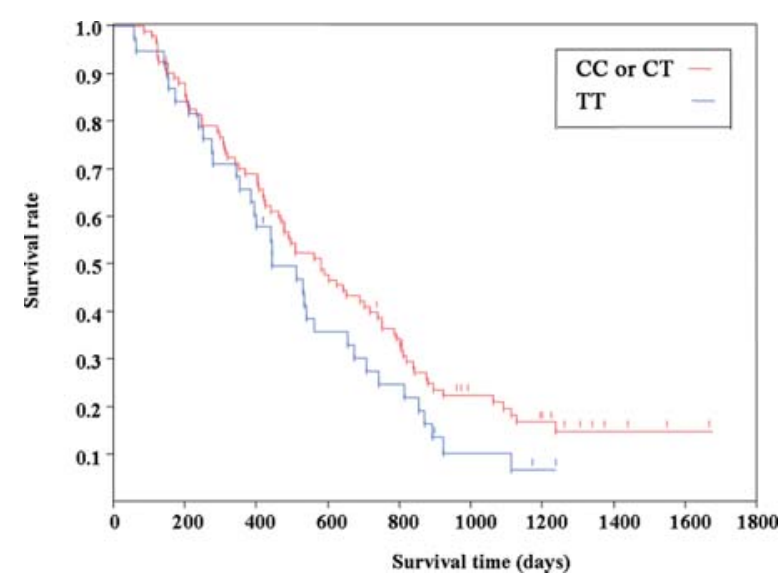

Figure 1. Comparison of survival time between patients with the TT genotype $(n=38)$ and those with the CT or CC genotypes $(n=94)$. The median survival of patients with the TT genotype was shorter, although not significantly, than that of patients with the CT or CC genotypes (log-rank test, $\mathrm{P}=0.144$ ).

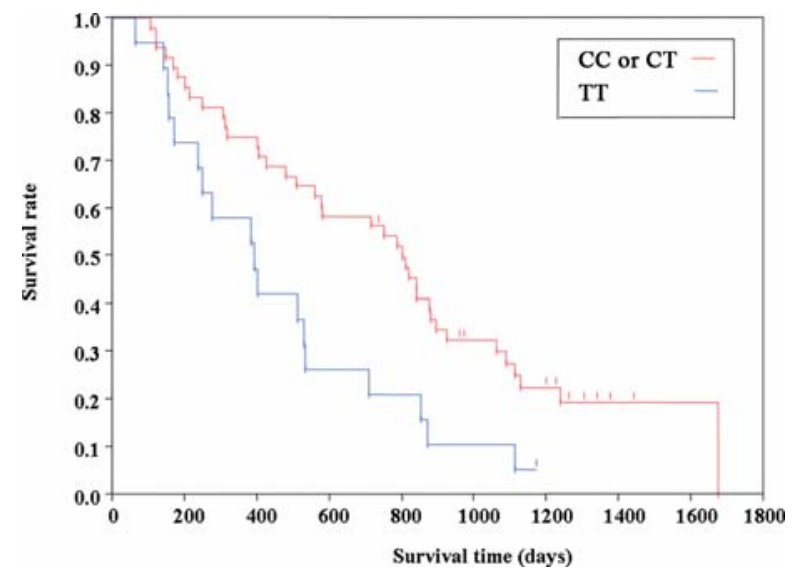

Figure 2. Comparison of survival time between patients with the TT genotype $(n=19)$ and those with the CT or CC genotypes $(n=49)$, focusing on patients with a smoking status of $<40$ pack-years. The median survival of patients with the TT genotype was significantly shorter than that of patients with the CT or $\mathrm{CC}$ genotypes (log-rank test, $\mathrm{P}=0.0084$ ).

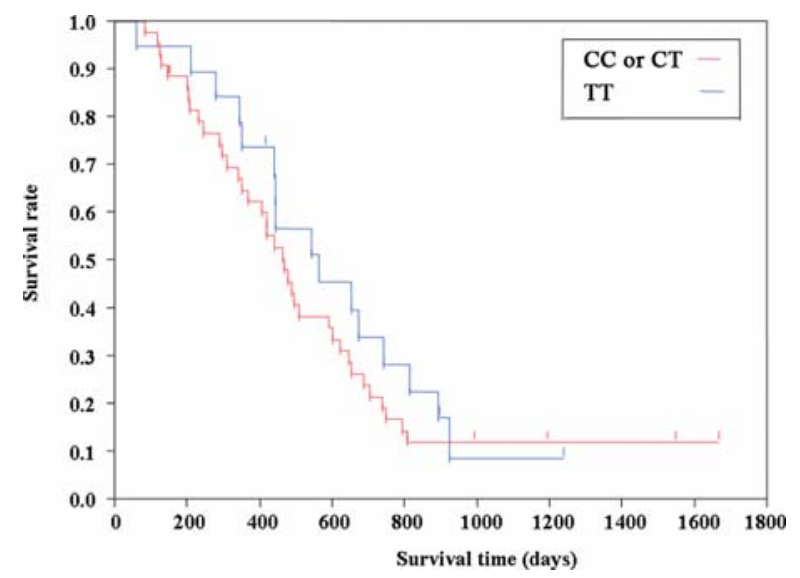

Figure 3. Comparison of survival time between patients with the TT genotype $(n=19)$ and those with the CT or CC genotypes $(n=45)$, focusing on patients with a smoking status of $\geq 40$ pack-years. There was no significant difference between these two groups (log-rank test, $\mathrm{P}=0.38$ ).
Table V. Association between the TGF-ß1 C-509T genotype and clinical characteristics of patients with a smoking status of $<40$ pack-years,

\begin{tabular}{|c|c|c|c|}
\hline \multirow[b]{2}{*}{ Clinical characteristics } & \multicolumn{2}{|c|}{ TGF-ß1 C-509T } & \multirow[b]{2}{*}{ P-values } \\
\hline & $\mathrm{CC}$ or $\mathrm{CT}$ & $\mathrm{TT}$ & \\
\hline \multicolumn{4}{|l|}{ Age } \\
\hline$<70$ years & 30 & 10 & 0.518 \\
\hline$\geq 70$ years & 19 & 9 & \\
\hline \multicolumn{4}{|l|}{ Gender } \\
\hline Male & 24 & 7 & 0.367 \\
\hline Female & 25 & 12 & \\
\hline \multicolumn{4}{|l|}{ Histological type } \\
\hline Adenocarcinoma & 38 & 17 & 0.325 \\
\hline Others & 11 & 2 & \\
\hline \multicolumn{4}{|l|}{ Performance status } \\
\hline $0-1$ & 45 & 17 & 1.000 \\
\hline $2-4$ & 4 & 2 & \\
\hline \multicolumn{4}{|l|}{ Stage } \\
\hline IIIA and IIIB & 9 & 3 & 1.000 \\
\hline IV & 40 & 16 & \\
\hline \multicolumn{4}{|l|}{ Lung metastasis } \\
\hline Yes & 14 & 7 & 0.508 \\
\hline No & 35 & 12 & \\
\hline \multicolumn{4}{|l|}{ Bone metastasis } \\
\hline Yes & 13 & 8 & 0.212 \\
\hline No & 36 & 11 & \\
\hline \multicolumn{4}{|l|}{ Brain metastasis } \\
\hline Yes & 10 & 5 & 0.598 \\
\hline No & 39 & 14 & \\
\hline \multicolumn{4}{|l|}{ Liver metastasis } \\
\hline Yes & 7 & 3 & 1.000 \\
\hline No & 42 & 16 & \\
\hline \multicolumn{4}{|l|}{ Adrenal metastasis } \\
\hline Yes & 6 & 3 & 0.702 \\
\hline No & 43 & 16 & \\
\hline
\end{tabular}

1.212-3.864; $\mathrm{P}=0.0106)$ was a significantly independent prognostic factor for survival (Table VII). PS could not be analyzed as the numbers were too small.

\section{Discussion}

This study shows no association between the TGF- $\$ 1$ polymorphism, C-509T, and survival in patients with advanced NSCLC. In patients with a smoking status of $<40$ pack-years, however, the TGF- $\$ 1$ polymorphism, C-509T, was significantly associated with the prognosis of advanced NSCLC, and the TT genotype was a poor independent prognostic factor for survival. To the best of our knowledge, this is the first study on the association between TGF- 31 polymorphisms and survival in patients with advanced NSCLC. 
Table VI. Univariable analysis of survival in patients with a smoking status of $<40$ pack-years.

\begin{tabular}{llll}
\hline Variables & HR & 95\% CI & P-values \\
\hline Age ( $\geq 70 /<70$ years) & 1.133 & $0.655-1.927$ & 0.650 \\
Gender (male/female) & 1.279 & $0.750-2.178$ & 0.364 \\
Histological type (other/adenocarcinoma) & 1.659 & $0.850-3.029$ & 0.132 \\
Performance status (2-4/0-1) & 2.026 & $0.690-4.786$ & 0.180 \\
Stage (IV/IIIA or IIIB) & 2.069 & $1.031-4.744$ & $0.0401^{\mathrm{a}}$ \\
TGF-B1 C-509T (TT/CT or CC) & 2.127 & $1.172-3.727$ & $0.0141^{\mathrm{a}}$ \\
\hline
\end{tabular}

a Statistically significant in Cox proportional hazard model analysis; $\mathrm{P}<0.05$.

Table VII. Multivariable analysis of survival in patients with a smoking status of $<40$ pack-years.

\begin{tabular}{llll}
\hline Variables & HR & $95 \%$ CI & P-values \\
\hline Histological type (other/adenocarcinoma) & 1.682 & $0.850-3.084$ & 0.123 \\
Stage (IV/IIIA or IIIB) & 2.001 & $0.994-4.598$ & 0.0521 \\
TGF-B1 C-509T (TT/CT or CC) & 2.201 & $1.212-3.864$ & $0.0106^{\mathrm{a}}$ \\
\hline
\end{tabular}

aStatistically significant in Cox proportional hazard model analysis; $\mathrm{P}<0.05$.

TGF- $ß$ signaling can inhibit tumor growth in developing tumors. However, in late-stage tumors, the very same pathway promotes tumor invasiveness and metastasis (17). Disruption of TGF- $\beta$ homeostasis occurs in several human cancers (3-5). Data from both experimental model systems and studies of human cancers have clearly shown that not only the ligand itself but also its downstream elements, are important in suppressing primary tumorigenesis in many tissue types (18). However, many human cancers, including lung cancer, often overexpress TGF- $\beta$. Furthermore, TGF- $\beta$ enhances the invasiveness and metastatic potential of certain late-stage tumors (19). This tumor-promoting effect is supported by the elevated levels of TGF- $\beta$ found in patients during the later stages of cancer, with its increased production being associated with increased invasiveness and poor prognosis in these patients (20-22). The role of TGF- $\beta$ in cancer progression and metastasis is generally accompanied by decreased or altered TGF- $\beta$ responsiveness and the increased expression or activation of the TGF- $\beta$ ligand (19). The loss of the TGF- $\beta$ response, which results in a lower inhibitory effect of TGF- $\beta$ on proliferation, has been associated with tumor development and/or tumor progression in many types of cancer $(23,24)$.

Although this was a small, retrospective study focused on patients with a smoking status of $<40$ pack-years, this study shows that the TGF- 31 polymorphism, C-509T, is significantly associated with prognosis in patients with advanced NSCLC and that the TT genotype is an independent prognostic factor for poor survival. Although TGF- 31 serum levels were not evaluated in this study, the results are reasonable as the $\mathrm{T}$ allele of the TGF- $\beta 1$ polymorphism, C$509 \mathrm{~T}$, is associated with increased serum levels of TGF- $\beta 1$
(11), and TGF- $\beta$ promotes tumor invasiveness and metastasis in late-stage tumors. On the contrary, the TGF- $\beta 1$ polymorphism, C-509T, was not associated with prognosis in heavy smokers. It is well known that cigarette smoking induces the activation of TGF- $\beta(15,16)$. Therefore, these results suggest that cigarette smoking has a greater influence on TGF- $\beta 1$ than the TGF- 31 polymorphism, C-509T. However, many other TGF- $\$ 1$ poly-morphisms are also known to exist, and therefore larger studies are required in order to confirm the association between TGF- 11 polymorphisms and tumor development or prognosis. Recently, inhibitors of TGF- $\beta$ signaling were developed for use in cancer treatments (17). The results from this study suggest that such treatments could be effective for certain patients with advanced NSCLC.

\section{References}

1. Massague J: TGF-beta signal transduction. Annu Rev Biochem 67: 753-791, 1998

2. Kato Y, Habas R, Katsuyama Y, Naar AM and He X: A component of the ARC/Mediator complex required for TGF beta/Nodal signalling. Nature 418: 641-646, 2002.

3. Blobe GC, Schiemann WP and Lodish HF: Role of transforming growth factor beta in human disease. N Engl J Med 342: 1350-1358, 2000.

4. Rich J, Borton A and Wang X: Transforming growth factor-beta signaling in cancer. Microsc Res Tech 52: 363-373, 2001.

5. Siegel PM and Massague J: Cytostatic and apoptotic actions of TGF-beta in homeostasis and cancer. Nat Rev Cancer 3: 807-821, 2003.

6. Derynck R, Rhee L, Chen EY and Van Tilburg A: Intron-exon structure of the human transforming growth factor-beta precursor gene. Nucleic Acids Res 15: 3188-3189, 1987. 
7. Cambien F, Ricard S, Troesch A, et al: Polymorphisms of the transforming growth factor-beta 1 gene in relation to myocardial infarction and blood pressure. The Etude Cas-Temoin de l'Infarctus du Myocarde (ECTIM) Study. Hypertension 28: 881-887, 1996

8. Langdahl BL, Knudsen JY, Jensen HK, Gregersen N and Eriksen EF: A sequence variation: 713-8delC in the transforming growth factor-beta 1 gene has higher prevalence in osteoporotic women than in normal women and is associated with very low bone mass in osteoporotic women and increased bone turnover in both osteoporotic and normal women. Bone 20: 289-294, 1997.

9. Kang HG, Chae MH, Park JM, et al: Polymorphisms in TGFbeta1 gene and the risk of lung cancer. Lung Cancer 52: 1-7, 2006.

10. Park KH, Lo Han SG, Whang YM, et al: Single nucleotide polymorphisms of the TGFB1 gene and lung cancer risk in a Korean population. Cancer Genet Cytogenet 169: 39-44, 2006.

11. Grainger DJ, Heathcote K, Chiano M, et al: Genetic control of the circulating concentration of transforming growth factor type beta1. Hum Mol Genet 8: 93-97, 1999.

12. Goldstraw P, Crowley J, Chansky K, et al: The IASLC Lung Cancer Staging Project: proposals for the revision of the TNM stage groupings in the forthcoming (seventh) edition of the TNM Classification of malignant tumours. J Thorac Oncol 2: 706-714, 2007

13. Yamada Y, Miyauchi A, Takagi Y, Tanaka M, Mizuno M and Harada A: Association of the c-509 $\rightarrow$ T polymorphism, alone of in combination with the $t 869->$ C polymorphism, of the transforming growth factor-betal gene with bone mineral density and genetic susceptibility to osteoporosis in Japanese women. J Mol Med 79: 149-156, 2001.

14. Sato F, Narita I, Goto S, et al: Transforming growth factorbeta1 gene polymorphism modifies the histological and clinical manifestations in Japanese patients with IgA nephropathy. Tissue Antigens 64: 35-42, 2004.
15. Wang RD, Wright JL and Churg A: Transforming growth factor-betal drives airway remodeling in cigarette smoke-exposed tracheal explants. Am J Respir Cell Mol Biol 33: 387-393, 2005.

16. Churg A, Tai H, Coulthard T, Wang R and Wright JL: Cigarette smoke drives small airway remodeling by induction of growth factors in the airway wall. Am J Respir Crit Care Med 174: 1327-1334, 2006.

17. Jeon HS and Jen J: TGF-beta signaling and the role of inhibitory Smads in non-small cell lung cancer. J Thorac Oncol 5: 417-419, 2010.

18. Markowitz SD and Roberts AB: Tumor suppressor activity of the TGF-beta pathway in human cancers. Cytokine Growth Factor Rev 7: 93-102, 1996.

19. Roberts $A B$ and Wakefield LM: The two faces of transforming growth factor beta in carcinogenesis. Proc Natl Acad Sci USA 100: 8621-8623, 2003.

20. Maehara Y, Kakeji Y, Kabashima A, et al: Role of transforming growth factor-beta 1 in invasion and metastasis in gastric carcinoma. J Clin Oncol 17: 607-614, 1999.

21. Picon A, Gold LI, Wang J, Cohen A and Friedman E: A subset of metastatic human colon cancers expresses elevated levels of transforming growth factor beta1. Cancer Epidemiol Biomarkers Prev 7: 497-504, 1998.

22. Wikstrom P, Stattin P, Franck-Lissbrant I, Damber JE and Bergh A: Transforming growth factor betal is associated with angiogenesis, metastasis, and poor clinical outcome in prostate cancer. Prostate 37: 19-29, 1998.

23. Kim SJ, Im YH, Markowitz SD and Bang YJ: Molecular mechanisms of inactivation of TGF-beta receptors during carcinogenesis. Cytokine Growth Factor Rev 11: 159-168, 2000.

24. Yanagisawa K, Osada H, Masuda A, et al: Induction of apoptosis by Smad3 and down-regulation of Smad3 expression in response to TGF-beta in human normal lung epithelial cells. Oncogene 17: 1743-1747, 1998. 